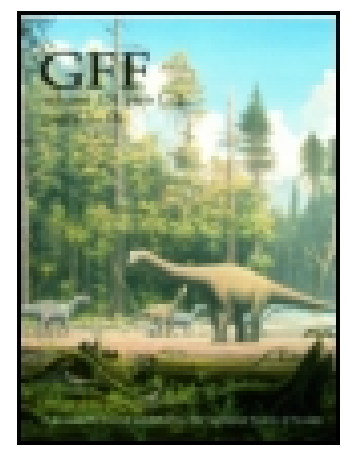

Geologiska Föreningen i Stockholm Förhandlingar

\title{
Schmalenseeia amphionura, en ny trilobit-typ
}

\author{
Joh. Chr. Moberg
}

To cite this article: Joh. Chr. Moberg (1903) Schmalenseeia amphionura, en ny trilobit-typ, Geologiska Föreningen i Stockholm Förhandlingar, 25:2, 93-101, DOI: 10.1080/11035890309443449

To link to this article: http://dx.doi.org/10.1080/11035890309443449

$$
\text { 曲 Published online: } 06 \text { Jan } 2010 .
$$

Submit your article to this journal $\pi$

$$
\text { 山 Article views: } 5
$$

Q View related articles $\square$

4 Citing articles: 6 View citing articles 
GEOL. FöREN. FÖRHANDL. N:o 219. Bd 25. Häft. 2. 93

Schmalensecia comphionurch, ell ny trilobit.typ.

Af

Joh. Cirr. Mobera.

(Härtill tafl. 4.)

För ett par år sedan erhöll Lunds Universitets GeologiskIlineralogiska Institution från G. C. voN Schmalexsée en del exemplar af det fossil, hvarom här är fråga. Materialet består väsentligen af hufvud- och stjertsköldar, inalles omkring 50 stycken, flertalet dock inycket fragmentariska. De härröra fri̊n zonen med Agnostus pisiformis ${ }^{1}$ och äro insamlade 1899 vid Köpings klint, Ö om Borgholın (Öland). § bifogad etikett hade fossilet betecknats såsom ,Linnarssonia occultas, en benämning, som dock ej kan bibehållas, då ju namnet Linnarssonia redan är taget $\mathrm{i}$ anspråk för ett brachiopodslägte. Det har derför synts mig synnerligen lämpligt att $\mathbf{i}$ stället uppkalla detta nya slägte efter fossilets upptäckare, den entusiastiske pionier på det geologiska området, till hvilken vetenskapen redan förut står i skuld för sã månget vackert fynd, under det att han sjelf väl knappast fått allt det erkännande hans ofta nog så mödosamma arbete förtjenat. Äfven etikettens artnamn, soccultas, har jag ersatt med det, som mig synes, mera expressiva amplionura.

Dă det nya slägtet uteslutande grundats pă föreliggande art, kan för närvarande ej.göras någon åtskilnad mellan slägt- och artdiagnos $\mathrm{i}$ den beskrifning, som här nedan skall lemnas. Några

$1 \hat{A}$ en af de fossilen bifogade etiketterna stod, i snmband med oboluskonglomeratet = Andraramskalken,, hradan fossilen tydligen hürröra frîn understa delen af zonen med Agn. pisiformis. 
allıänna anmärkningar angående olenidskiffrarnes trilobitfauna torde dock dessförinnan vara på sin plats, såsom den bakgrund, mot hvilken först fossilets betydelse kan framstå i sin rätta belysning.

Inom hela kambrium äro, efter allt hvad vi nu veta, trilo. biterna systemets formrikaste, vigtigaste djurgrupp. Systemets serier ha ocksi fătt benämningar efter de trilobitfamiljer, som förherrska $i$ de shilda serierna. Inom den öfversta af dem äro, frănsedt ett fătal (4) Agnostider, Oleniderna allenarådande, hvarför den ïfven kallats olenidserien, eller också, på grund af den petrografiska utvecklingen, olenidskiffern. Då den rådande djurgruppen sålunda i hufvudsak tillhïr en enda familj, gör olenid. skifferns fauna, särskildt som de skilda arterna hvar för sig uppträda $i$ öf verväldigande massor, ett synnerligen starkt intryck af formfattigdom. Vi erinra oss ju också, hurusom ANGeLix på sin tid, innan ännu lagrens stratigrafi var närmare känd, just på grund af denna formfattigdom förleddes att anse olenidserien äldre än paradoxidesserien.

Af de svenska olenidskiffrarnes många zoner är det endast Acerocarelagren och Pelturalagren, som i nyare tid blifvit något wera ingånde genomarbetade, de förra af MoBERG och MöLLER, de senare af Limsarsson. Men hvad de öfriga beträffar kvarsta vi $\mathrm{i}$ det stora hela ännu på samma punkt, som Arorelis $1854 \mathrm{j}$ P'aleontologia scandinavica. Ty frånsedt Agnostus-arterna känna vi för närvarande frăn olenidskifferns äldre zoner endast 14 (eller, om Ctenopyge flagellifera ANG. sp. här skall medräknas, 15) trilobiter, hvilka dock alla utom en, nämligen Liostracus? superstes LiNRs, redan omnämnas af Avaelis. Vid nyssnämda, efter Axaelrss tid tillkomna bearbetningar af trilobitfaunan $i$ olenidskiffrarnes båda yngsta zoner blef artantalet mer än fördubbladt, ett resultat som, efter hvad det kunde tyckas, borde uppmuntra till en revision äfven af de äldre zonernas trilobiter. Men en dylik granskning är å andra sidan också förenad med synnerligen stora svårigheter. ANGeliss lakoniska, föga distinkta diagnoser och hans restaurerade, delvis intetsägande afbildningar 
GEOL. FÖREన. FÖRILANDL. N:o 219. Bd 25. Häft. $2 . \quad 95$ tillåta sällan enbart för siğ säkra identifieringar. Att under lupp åt sig. utsöka brukbart material bland millioner illa beva.rade fossilfragment, ür redan det ett svårt, både ögonfördèrrande och tidsödande arbete; och att sedan rätt sammanföra de i regel skilda kroppsdelar, som tillhöra en- och samma art, kräfver bäde varsamhet och urskiljning. När så härtill kommer den habituella olikhet ett fossil påtryckes, allt efter som det är beraradt $i$ skiffer eller orsten, inses lätt att granskningen ifràga ingalunda hör till de $\mathbf{i}$ vanlig mening tacksamma uppgifterna.

Som ofvan nännts ha de båda yngsta zonernas trilobitfauna efter AxGeuriss tid reviderats ocli de närmast äldre, eller lagren med Eurycare och Jeptoplastus, bearbetas för närvarande å Lunds Geol.-Nlin. Institution sedan ett par års tid af kand. E. PElssox, som dock änun är långt ifrån fürdig med sitt arbete. Detta oafsedt återstår ändå mycket, innan vi kunna sägas ha kommit till en någorlunda tidsenlig kännedom om trilobitfaunan i Sveriges olenidskiffrar.

Och dock erbjuder denna fauna, tillhörig lager som stå sả när öfvergången från kambrium till undersilur, $i$ många hänseenden ett alldeles särshildt intresse. I dessa lager ville man gerna rainta sig något annat än den enformiga olenidfaunan. IHär, kunde det tyckas, borde man ega rïtt att hoppas finna rötterna till den undersiluriska trilobitfaunans månggreniga stamtrïd, vare sig $i$ form af mera direkta fürelöpare eller $i$ form af mindre differentierade kollektivtyper. Vore det nu så, att man, oaktadt grundliga, offer vidt skilda omraiden utsträckta undersükuingar, ej lyckades påvisa năgra dylika, hade man für fenomenets förklaring endast att välja mellan tvă olika antaganden, let ena, att stamformerna i frága visserligen lefvat inom samma område som oleniderna, men ej blifvit eller ej kunnat blifva bevarade, det andra, att do haft ett annat utbredningsområde, från hvilket deras efterkommande sedermera invandrat. Det förstnämnda kan tydligen utan vidare förkastas, det andra åter skulle leda oss direkt till det gångna seklets så ofta missbrukade, ej sillan helt godtyckliga migrationsteorier. Särskildt i detta fall 
synas dylika mindre tilltalande, enär man under dylika förutsätt. ningar har svårt att förklara den i det stora hela så ensartade utbildning, som olenidskiffrarne egn allestädes inom det vidstrïckta utbredningsområdet. ${ }^{1}$ För närvarande torde emellertid en mer eller mindre äfventyrlig diskussion af migrationsteorier vara mindre af behofvet påkallad, än ett noggrannt genomletande af olenidskiffrarne. Helt visst skall då månget fossil anträffas, egnadt att sprida ljus öfver sambandet mellan den kambriska och den undersiluriska trilobitfaunan, äfven om utvecklingsgången $\mathbf{i}$ alla dess detaljer ej dermed genast kan följas. Ett stöd för denna min förvissning är just det af v. ScmMaLexsée gjorda fynd, som här nedan beskrifves. Trilobiten i fråga bildar så att säga en typ för sig, som visserligen $i$ en eller annan karakter erbjuder likhet med andra, yngre former, utan att dock någon egentlig sammanställning med dessa kan göras.

\section{Schmalenseeia amplionura n. g. et n. sp. Tafl. 4, fig. 1-10.}

En af våra minsta trilobiter - hela kroppslängden torde väl aldrig ha öfverskridit $7 \mathrm{~mm}$ - är den dock äfven vid mycket vexlande dimensioner alltid så ensartadt utvecklad, att den med all sïkerhet är att räkna som en själfständig art, ej ett ungdomsstadium. Vanligast ärọ isolerade hufvud- och stjertsköldar, särskildt såsom fragment, bildade af glabellan eller af pygidiets rhachis med närmaste delar af brämet. Af thorax ha endast sparsamt fragment af enstaka segment anträffats. Sannolikt füreligger också en lös kind.

'I en uppsats, On the sLingula Flagss or sFestiniog Groups of the Dolgelly District (Geolog. Mrag. 1865) kommer BELT, just på grand af den skarpa skilnaden mellan ofre kambriums och undersilurens trilobitfauna, in p̊̊ samma spörsmill. Han anser det sej osannolikt,, att den isldsta undersiluriska faunan ä de iterflyttande afkumlingarna till en emigreral underkambrisk fauna. Vore det ej möjligt, frîgar han, att en köldperiod rillat ernigrationcn, en rarmare itterṇttandet? 
GEOL. FÖREN. FÖRIIANDL. N:o 219. Bd 25. Häft. 2. 97

Hufvudskölden, i det stora hela lindrigt hvälfd, har brämets perifera del nästan plan. Den är ungefär hälften så lăng som bred, med rak bakre rand. Dess yttre kontur fảr också form af en halfcirkel, ur hvilken dock fncialsuturerna, hvilkas båda grenar utmynna i ytterranden, å hvardera sidan utskïra ett svagt kilformigt, utăt bredare parti. Randfåra saknas. Skalet är glatt.

Glabellan, som nackringen inberäkuad når vid pass tvă tredjedelar af hufvudsköldens hela längd, upptager ej fullt en femtedel af bakre randen och är omkring dubbelt så lâng som bred. Sakta afsmalnande framåt, är den i tvärrigtningen väl hrälfd och i längdrigtningen framåt något nedböjd, detta dock füga mer än angränsande delar af fasta kinderna. Från dessa skiljes glabellan genom fina, men tydliga, raka axelfåror, hvilka sluta sig tillsammans vid glabellans främre, afrundade ända, der de äro nigot starkare intryckte än $i$ öfrigt. Från midten af glabellans främre ïnda löper en fin, jemnbred, upphöjd list rätt fram öfver brämet ända bort till ytterranden. Det främre, $i$ det stora hela platta, brämet är närmast glabellan något nedtryckt

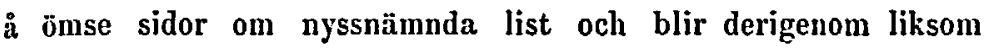
deladt i två svagt hvälfda hälfter. Den tydligt markerade raka nackfiran, som är något smalare än nackringen, kan följas vidare ett litet stycke in på fasta kinden, men blir der genast alldeles utplånad. Framom nackfâran märkas å glabellan ytterligare 3 stycken raka trürfåror, som $\mathrm{i}$ mellersta tredjedelen äro något smalare, svagare intryckta än närmare axelfărorna. Glabellan blir sålunda (om nackringen medräknas) fördelad i fem segment, alla med afrundad yttre kontur. Af dessa segment äro nackringen och det närmast bakom ändloben befintliga segmentet smalare (i kroppens längdrigtning räknadt) än de båda dem emellan liggande segmenten. Ïndloben åter upptager i kroppens längdrigtning lika stort utrymme som de båda der bakom liggande segmenten jemte dem åtskiljande fåra tillsammans och får derföre form af en ovalt rundad, längsstäld, kullrig knapp. Palpebralloberna, framtill börjande midtför glabellans första tvärfảra och med bakre ändan slutande $\mathbf{i}$ jemnhöjd med tredje tvär- 
fảran, äro lindrigt bågböjda, något uppåtvikna. Facialsuturens grenar gå $i$ det närmaste rätlinigt, rigtade suedt framåt utåt, något divergerande. Den bakre grenen skür ytterranden $i$ jemn. höjd med glabellans främsta tvärfăra. Enär samtidigt hufvudets bakre rand bildar ett skarpt hörn med den yttre randen, kommer sålunda fasta kindens bakie del att utât starkt tilltaga i bredd. Den mellan ögat och glabellan belägna delen är helt smal, ungefär hälften så bred som närliggande del af glabellan. Strax framom ögat, innerst $\mathbf{i}$ vinheln mellan främre facialsuturen och glabellan, mär. kes å hvardera sidan en väl markerad liten knöl, eller rättare en nágot på längden utdragen ansvällning. Mellan palpebralloberna och glabellans fränre ända slutta fasta kinderna framom de nyssuämda ansvällningarna lastigt mot det främre brämet, hvars bakre gräns sâlunda blir ganska markerad.

Det $\mathrm{i}$ fig. 3 afbildade föremålet synes möjligen vara en lös kind med tillhörande öga. Begränsningen $\ddot{i r}$ ej rundt om alldeles klar, men tyckes dock passa godt med utskïrningen mellan facialsuturens grenar. Några ögonfacetter ha ej kunnat iakttagas. Som endast det afbildade exemplaret anträffats, är min tolkning af dess natur något osäker. Ammärkas bör dock, att någon förvexling med vare sig glabellans ändlob eller ansvällningen vid ïnlobens sida jemte dem angränsande delar af främre brïmet ej kan iftågasättas. Ty i förra fallet skulle den från glabellan utgående smala listen varit synlig, $i$ det senare skulle, i motsats till hrad nu är fallet, funnits en stark sluttning mellan ansrällningen och brïmet. Ej heller kan föremålet vara fragment af nagon Agnostus.

Pygidiet påminner till sin allmänna habitus ej så litet om en Amplion, något som derföre framhållits genom det artnamn som valts. Dock sluttar det mera takformigt ât båda sidor frán en nïstan horisontel, d. v. s. baktill föga nedböjd, medellinie. Främre randen är starkt bakatböjd, den bakre (yttre) beskrifver deremot, atminstone hos äldre individ, en mycket lindrigare båge, som $\mathrm{i}$ detta fall ocksi tyckes ha en grund inskürning bakom rhachis, nágot som dock möjligen blott beror på lædering. Största bred- 
GEOL. FöreN. FöRHANDL. N:o 219. Bd 25. Häft. 2. 99 den ligger hos dylika exemplar något bakom pygidiets halfva längd. Yngre individ deremot torde säkerligen ej haft pygidiets bakre rand urnupen och deras maximibredd synes ha legat något längre fram. Rhachis, som når ungefär två tredjedelas af pygidiets längd, bildas af sex genom smala raka trärfåror skilda ringar, af lrilka dock den, som bildar yttersta spetsen, är otydlig. Sockertoppformig, begränsad af fina men tydligt markerade, något stängda, utăt konvexa axelfåror, är rhachis ganska väl hvälfd, men skiljer sig dock, på grund af brämets starka sluttning utåt, ej sĩ mycket från detta. $\AA$ bättre bevarade (yngre?) exemplar är rhachisringarnes midt något ansvälld eller möjligen starkare lvälfd, utan att dock verkliga tuberkler derigenom bildas. Brïmets båda hälfter, som i sidopartiernas perifera delar bli svagt konkava, fördelas genom från rhachisringarnes bakre rand utgående, mer och mer rakt bakåt rigtade, fina lister i lika mănga sragt konkava fält, livarjemte äfven fältet bakom spetsen af rhachis är deladt midt itu genom en liknande smal list. $\AA$ somliga större pygidier ser det nästan ut som bildades dessa lister på så sätt, att brïmet $i$ lıvarje fält stupar framåt, så att det $i$ sin främre rand kommer lägre än närmast framför liggande fälts bakre rand. Listerna ha $i$ brümets frïmre delar ett svagt $S$ formigt förlopp, i det att de såväl nürmast rhachis som utmed ytterranden äro rigtade något litet mera rïtt utä ïn för öfrigt ï fallet. Yttre randen tyckes vara alldeles jemn, utan inskärningar i gränsen mellan de skilda fälten.

Af thorax trïffas endast fragment af isolerade segment, mestadels smala rännformiga pleuror. (Jfr fig. 4). Af dessa, sìvill som af ett större vid ett pygidium vidhängande fragment af sista thoraxledet (se fig. 7), vill det synas som hade byggnaden af thorax $i$ allmänna drag öfverensstämt med pygidiets främre del. Ett par jemförelsevis bredare fragment (fig. 5, 6) afrika äfven derigenom, att en del af segmentet är tydligt fáradt, denna del torde tillhüra rhachis i kroppens främre del. Endast de afbildade fragmenten äro funna. 
Jemte Schmalenseeia anträffas blott Agnostus pisiformis (rïtt ymnigt) samt ett par ostrakoder (mera sparsamt).

$\AA$ en del bättre bevarade exemplar ha erhållits följande mảtt $\mathrm{i} m m$.

\begin{tabular}{|c|c|c|c|c|}
\hline \hline Hufvud. & Iela längden. & $\begin{array}{c}\text { Bredden } \mathrm{i} \\
\text { bakre randen. }\end{array}$ & $\begin{array}{c}\text { Gackingens } \\
\text { Glabellans } \\
\text { Jängd. } \\
\text { bredd, i krop- } \\
\text { pens trär- } \\
\text { dimension. }\end{array}$ \\
\hline N:r I . . . . . . & 1.8 & 3.6 & 1.3 & 0.7 \\
, II . . . . . . & 1.5 & 2.8 & 1.0 & 0.6 \\
. III . . . . . . &.- & 2.6 & 1.0 & 0.6
\end{tabular}

\begin{tabular}{|r|c|c|c|c|}
\hline \hline Pygidium. & IIela längden & $\begin{array}{c}\text { Största } \\
\text { bredden. }\end{array}$ & $\begin{array}{c}\text { Längden af } \\
\text { rhachis. }\end{array}$ & $\begin{array}{c}\text { Bredden af } \\
\text { rhachis. }\end{array}$ \\
\hline Nir I . . . . . & 1.6 & 2.5 & 1.0 & 0.8 \\
, II . . . . . & 1.6 & 2.3 & 1.0 & 0.7 \\
, III . . . . & 1.5 & 2.0 & 0.8 & 0.6 \\
IV . . . . . & 1.4 & 1.8 & 0.8 & 0.6 \\
I. . . . . & 1.2 & 1.7 & 0.7 & 0.4 \\
\hline
\end{tabular}

Af dessa mått tyckes framgå, att pygidiet, såväl som dess rhachis, tillväxer mera på bredden än på längden.

Jemföres Schmalenseeia med förut kända trilobiter, finner man genast, att den ej är att ställa bland Oleniderna. Facialsuturens förlopp liksom äfven $i$ viss mån pygidiets byggnad erbjuda då större likhet med Chirurida eller Encrinurida, să som de t. ex. representeras af Amphion Fischeri Erchw. eller Cybele bellatula DAws. Hufvudets främre del med sitt breda bräm erinrar åter möjligen något om Anomacare eller om vissa andra Conocoryphida, men dylika likheter sträcka sig endast till enstaka delar af skalet och kunna ej tillmätas någon betydelse såsom stöd för en verkligt analog systematisk ställning. För nürvarande kunna vi således ej inordna Schmalenseeia i nå. 
GEOL. FÖREN. FöRHANDL. N:o 210. Bd 25. Häft. 2. 101 gon känd familj, utan hafva att betrakta den såsom en egen typ, stående närmast Chirurida bland hittills kända former.

lund $\mathfrak{i}$ jan. 1903. 